\title{
Correction to: Modeling and Negotiating Service Quality
}

Salima Benbernou, Ivona Brandic, Cinzia Cappiello, Manuel Carro, Marco Comuzzi, Attila Kertész, Kyriakos Kritikos, Michael Parkin, Barbara Pernici, and Pierluigi Plebani

\section{Correction to:}

Chapter "Modeling and Negotiating Service Quality" in: M. Papazoglou et al. (Eds.): Service Research Challenges and Solutions for the Future Internet, LNCS 6500, https://doi.org/10.1007/978-3-642-17599-2_6

In the original version of this chapter, the affiliation of Barbara Pernici was incorrectly indicated as "Tilburg University, The Netherlands". It was corrected to "Politecnico di Milano, Italy" 